\title{
EL GUSTO POPULAR Y SU EXPRESIÓN ESTÉTICA EN LA CAPILLA DE LA ASUNCIÓN: LAVALLE, MENDOZA (ARGENTINA)
}

\author{
POPULAR TASTE AND ITS AESTHETIC EXPRESSION \\ IN THE ASUNCIÓN CHAPEL: LAVALLE, MENDOZA \\ (ARGENTINA)
}

\section{VERÓNICA CREMASCHI ${ }^{1}$}

\section{RESUMEN}

En la capilla y fiesta de la Asunción en Lavalle, Mendoza (Argentina), se manifiestan las características propias de las producciones populares latinoamericanas, sus particularidades estéticas son factibles de valoración a partir de parámetros propios latinoamericanos. Las minusvaloradas expresiones populares constituyen parte fundamental de nuestro acervo cultural, estético e identitario, y deben ser estudiadas y difundidas para su correcta valoración. Encontrando parámetros estéticos comunes se contribuirá al diálogo entre los países latinoamericanos y se evidenciarán estratos culturales comunes.

Palabras clave: Valoración estética, gusto popular, identidad.

\section{ABSTRACT}

In the Chapel and celebration of the Asuncion in Lavalle, Mendoza (Argentina), characteristics of Latin American popular productions are present and a particular aesthetics can be valued in terms of Latin American parameters. These undervalued popular expressions constitute a fundamental part of our cultural heritage, aesthetics and identity. They should be studied and disseminated in order to appreciate their real value. Finding common aesthetic parameters and cultural strata will contribute to a dialogue between Latin American countries.

Keywords: Aesthetic valuation, popular taste, identity.

Recibido: 09.09.11. Aceptado: 23.02.13.

${ }^{1}$ Licenciada y profesora en Historia del Arte U.N. Cuyo, becaria de CONICET-CCT-Mendoza. E-mail: vcremaschi@conicet.gov.ar 
a CAPILla de la Asunción de la Virgen del Tránsito en Lavalle es un ejemplo valioso de las iglesias del desierto mendocino. Las obras de arquitectura religiosa diseminadas en esta zona han sido, como ha destacado Vicente(2009), tradicionalmente valoradas por su antigüedad y por haber resistido en pie a los distintos movimientos sísmicos sucedidos luego de su creación. Es decir, por asuntos históricos y técnicos que no han contemplado aspectos estéticos.

Sin embargo, estas construcciones poseen características que las hacen valiosas en cuanto que son productos estéticos-culturales populares que encarnan parte de nuestra identidad expresiva.

Primeramente debe comprendérselas como productos del mestizaje, es decir como objetos artísticos "impuros", resultado de la combinación de más de una influencia. Esta característica, común a toda Latinoamérica, no es un accidente sino una parte esencial, una línea central de nuestra identidad (Fernández Retamar, 2004). Destaca, además, que este término fue empleado por Martí como una señal distintiva de nuestra cultura, compuesta por descendientes de aborígenes, de europeos, de africanos.

Las capillas del desierto lavallino son claros ejemplos de las tensiones, conversaciones, resistencias y asimilaciones que han existido y existen entre las parejas dínamos de lo foráneo y de lo autóctono, de lo culto y de lo popular, que constituyen nuestra identidad.

No asumir nuestra realidad cultural y étnica mestiza sería negarnos a nosotros mismos y negar a los habitantes del desierto mendocino que han dado nacimiento a las capillas. No podemos continuar sosteniendo la concepción ficticia de que somos lo más europeo de la América Latina y negar una parte de nuestro pasado que existió y un presente que existe y que reclama ser visto, escuchado. Para ello es necesario crear nuestros propios criterios de valoración que nos den herramientas para comprendernos sin temores ni prejuicios.

\section{¿NUESTRA DEPENDENCIA CULTURAL?}

Próspero invadió las islas, mató a nuestros ancestros, esclavizó a Calibán y le enseñó su idioma para entenderse con él: ¿qué otra cosa puede hacer Calibán sino utilizar ese mismo idioma para maldecirlo, para desear que caiga sobre él la 'roja plaga'?'(Fernández Retamar, 2004).

Fernández Retamar (2004) ha tomado el cuento "La Tempestad" de 
Shakespeare y lo ha utilizado como metáfora para evidenciar la situación histórico-cultural de Latinoamérica.

El autor ha identificado los personajes con los distintos actores que intervienen en la realidad latinoamericana. El personaje de Próspero encarna lo europeo que, mediante la fuerza, somete y esclaviza al pueblo latinoamericano, simbolizado por Caliban; Próspero lo educa en su cultura, costumbres y lengua. Sin embargo, Caliban, personaje deforme que ha sido sometido, utiliza las armas culturales que ha aprendido del europeo Próspero y las vuelve contra él, en una actitud de rebeldía.

Las producciones estéticas populares transitan un recorrido similar a lo largo de la historia del arte latinoamericano. Se puede observar cómo las formas foráneas intentan ser impuestas a los pueblos oprimidos, estos últimos las adoptan, "aprehenden" las técnicas y las reutilizan de manera particular, imprimiéndoles características propias que las hacen diferentes a las formas que las "originaron". Es decir, terminan siendo utilizadas con un sentido nuevo, como hace Caliban con el lenguaje, para "reírse" de quien las promovió.

El resultado de esta actitud "calibanesca" son formas marginales "de resistencia" a las expresiones impuestas, correspondientes al arte culto. Estas maneras de expresión, por lo general, afloran en espacios alternativos, no oficiales, no legitimados y alejados de las instituciones y de las políticas gubernamentales.

Para definir estas expresiones populares de resistencia la Dra. Vicente (2009) ha utilizado el término compuesto de "mambí-forme". El concepto de mambí, cuyo origen es poco certero, hace referencia a los insurrectos que lucharon con sus machetes en las guerras de independencia de Santo Domingo. Luego, este término se hizo extensivo a los cubanos que se independizaron, con técnicas similares, cincuenta años después.

Retamar Fernández(2004) también alude al término mambí para destacar que un vocablo con intenciones ofensivas, designado por el opresor, puede ser resignificado por el oprimido y su valor negativo puede ser transformado en valor positivo:

Nos llaman mambí, nos llaman negro para ofendernos, pero nosotros reclamamos con un timbre de gloria el honor de considerarnos hijos de mambí, descendientes de negro alzado, cimarrón independentista[...] (Fernández Retamar, 2004: 37).

Es así que lo "mambí-forme" alude a las formas estéticas de resistencia 
que no siguen los ejemplos externos de forma pasiva, sino que, si bien utilizan el lenguaje (entendemos el formal como un tipo de lenguaje) impuesto, éste es resignificado, reorientado voluntariamente con fines específicos.

Ejemplo de esto es la riqueza y variedad en el arte latinoamericano, si bien las formas impuestas fueron españolas, a partir del circuito imposición -aprehensión- resistencia, se originaron estéticas diversas en las distintas formas del continente.

\section{EL CASO DE LA CAPILLA DE LA ASUNCIÓN DE LA VIRGEN DEL TRÁNSITO}

El pueblo de Asunción, distante ochenta kilómetros al norte de la capital de Mendoza, se encuentra enclavado en una zona desértica y árida. El paisaje, en el que predomina el color marrón, con vegetación baja, crea una atmósfera monótona, sensación que se intensifica debido a que la distancia no permite tener como punto de referencia cardinal la Cordillera de los Andes, mojón casi natural de cualquier mendocino.

El pueblo de Asunción carece del trazado regular, símbolo de lo civilizado, de lo moderno, de lo positivo, de la Mendoza racional y progresista (Ponte, 1999). Aquí la relación con la naturaleza se ha dado de manera espontánea. Se percibe un diálogo sutil del hombre con su entorno inmediato.

Sin embargo, si consideramos que el espacio habitado es una simbolización espontánea del espacio social, y a su vez el espacio social se retraduce en el espacio físico (Bourdieu, 2000), comprendemos que no todo es aleatorio o espontáneo.

Es así que la capilla en cuestión ha sido ubicada sobre un médano, lo que le otorga jerarquía y la posibilidad de ser vista con facilidad desde el pueblo. En este sentido, respondió, en un principio, a la categoría de forma impuesta, debido a que fue parte, en la Mendoza colonial, de una red de iglesias dispuestas estratégicamente para evangelizar a los habitantes de la zona.

No existen muchos datos de la fundación de esta capilla. Se cree que fue construida para honrar una imagen que se trajo de Chile alrededor de 1700. En los libros parroquiales de 1792 ya aparece mencionada por el presbítero Dr. Ochoa y Monclada, en sus visitas a las doctrinas. Como testimonio de su antigüedad alberga una cruz tallada con distintas fechas que se suceden a partir de 1883, en las que arribaron al paraje los misioneros para colonizar y predicar el evangelio (Proyecto de Ley 156, 2007). 
Sin embargo, esta forma impuesta ha sido aprehendida y resignificada, transformada en una expresión "mambí- forme" de resistencia, debido a que en ella afloran manifestaciones populares que exceden los ritos y costumbres de lo católico "culto".

Arquitectónicamente, esta capilla está constituida por una sola nave más larga que ancha, de gruesos muros de adobe. No posee claristorios ni aventanamientos, la luz procede únicamente de la puerta de ingreso, tampoco, ábside, ni coro. A la izquierda del altar, en una de las paredes laterales, se encuentra una puerta que comunica a dos oficinas contiguas. No posee reclinatorios y únicamente existen dos bancos dispuestos contra las paredes laterales.

El techo se presenta a dos aguas, aunque levemente inclinado; en el interior está revestido en caña y las cabreadas, de fuertes quebrachos achuelados, se encuentran dispuestas a la vista.

Esta austeridad formal, cuya tipología se desprende de modelos europeos, contrasta con la profusión de elementos que se encuentran decorando el altar principal.

La imagen más antigua que existe en la capilla representa a la Virgen María en su advocación de Virgen del Tránsito y no supera los cincuenta centímetros de altura. En situaciones cotidianas, es decir cuando no es sacada en procesión en las festividades, se encuentra sobre el altar principal en una pequeña ermita de tonalidades azulinas con decoraciones realizadas a mano.

Hasta el momento se han descripto los aspectos formales oficiales de la capilla de Asunción, sin embargo los lugareños han producido una reorientación en esta estética impuesta, importada por manos extranjeras "cultas".

La estética "mambí-forme" ha encontrado un lugar de surgimiento propicio en el pueblo de la Asunción, debido, entre otras realidades, a la distancia que lo separa de la capital de Mendoza y por ende de las instituciones, como la Iglesia, que tienden a regular estas prácticas.

Es así que, a lo largo del tiempo, se ha ido concretando la creación colectiva con exvotos que se encuentra en el altar, rodeando la imagen pequeña. En torno a ella se aprecia una obra estética en continua creación, recreación y crecimiento.

Allí podemos encontrar mayormente flores que adornan el altar y lo cubren casi completamente. Abundan las de fuertes colores como rojos, naranjas, amarillos, fucsias. Hay, además, estandartes bordados en lentejuelas brillantes, con mensajes y nombre de los oferentes. También, láminas y reproducciones de imágenes religiosas, canastitas de papel, lazos de colores, adornos hechos con plumas naturales, floreritos improvisados con elemen- 
tos hallados o encontrados, velas apagadas, velas prendidas, paquetes cerrados dispuestos frente a la imagen. El color explota como una provocación frente a la sobriedad y a la austeridad de la capilla.

El cofre, donde se cree que originalmente se trajo la imagen de la Virgen, ha sido forrado casi completamente en una tela que pareciera ser de tapicería con abundantes motivos florales. Sobre él, que aún conserva parte de su color "original" y que sirve de protección cotidiana a la imagen, hay una pequeña corona plástica plateada con imitación de piedras preciosas en tonos verdes y azules que, por cierto, no tiene valor material, sino simbólico. Es un producto de uso ordinario pero está cargada de una gran fuerza evocativa, sobre todo debido a que ha sido colocada en la parte superior. Frente al altar, sobre el piso, hay algunos candelabros de bronce, de chapa y una araña que ha dejado de ser de colgar y ha sido transformada en candelabro de pie.

La premisa estética parece ser la de la superabundancia, no existe una búsqueda de simetría, de orden o de estructura. Los objetos crecen orgánicamente sobre, a los lados y a los pies del altar principal. No es obra de una sola persona sino de muchas, no es obra de un día sino de muchos. Obra que cambia, que crece. No está compuesta de elementos valiosos, sino que el lugar, en el altar, acentúa su valor simbólico. Son elementos cotidianos, ordinarios, cuyo valor se incrementa a partir de su condición de ofrendas.

La imagen también ha sido "intervenida". Es una representación de la Virgen del Tránsito, esta advocación hace referencia a la asunción, al tránsito de la tierra a la gloria celestial en cuerpo y alma, por haber sido inmaculada. Se encuentra vestida, siguiendo el colorido tradicional de la advocación, con una túnica blanca y un manto de color celeste. Sin embargo, las telas escogidas para su atuendo son de un brillo novedoso, adornadas con puntillas, tules con pequeños brillantitos y guipur. Los labios y los ojos han sido evidentemente retocados y se presentan lozanos en contraste con la degradación que ha sufrido el rostro.

Las tradicionales "imágenes de vestir", muy populares en la época colonial, eran en realidad maniquíes que solamente tenían talladas o fundidas las manos, el rostro y, en algunos casos, los pies. A pesar de estar vestida, la imagen que nos compete es una talla completa, es decir, se ha tallado completamente el cuerpo con su vestuario correspondiente. Sin embargo, el gusto popular se ha manifestado y ha decidido engalanarla con vestidos, a pesar de que esta acción no estuviera prevista en la pequeña imagen "original”. Por ello sólo asoma del pomposo vestuario la cabeza de la virgen, quedando ocultos manos y pies.

La evidencia de la apropiación y reorientación estético-formal que pre- 

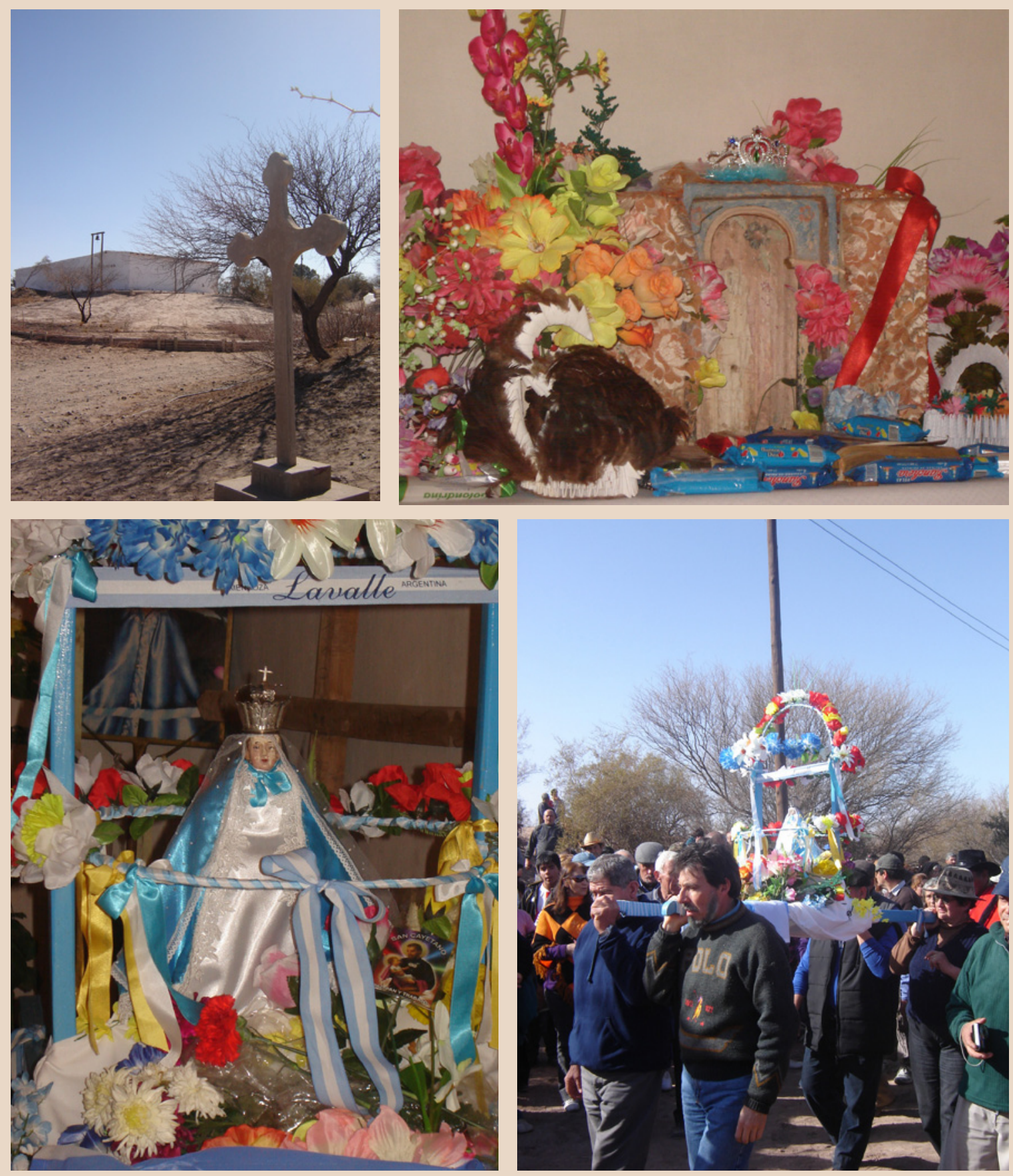
senta la imagen se acentúa durante la conmemoración de la asunción de la Virgen, los 15 de agosto.

Durante el fin de semana el pueblo realiza una fiesta muy popular que culmina con la procesión de la Virgen por el pueblo.

Esta fiesta, si bien es una fecha oficial, se ha transformado en un hito en el año de los habitantes del pueblo. Todos participan activamente de los festejos, se improvisan bodegones que ofrecen comidas de la zona, en mesones comunitarios regados de abundante vino y cerveza. Muchos bodegones son animados por guitarreros que, sin escenarios ni micrófonos, cantan tonadas y otros ritmos cuyanos. El menú consiste mayormente en chivo, animal que es faenado, cuereado y cocinado al aire libre. La concurrencia es muy grande, participan pobladores de comunidades vecinas y gente proveniente de la ciudad.

Este contexto sirve de marco a la procesión, culminación de las festividades. Para la ocasión, la imagen es engalanada por los pobladores y turistas más que de costumbre. Todos colaboran en un ir y venir de personas que colocan banderas, flores y cintas, generando que el colorido "calibanesco", prácticamente, devore, engulla a la imagen de la virgen oficial.

Vestida de orgulloso color y abundancia latinoamericana, que contras-

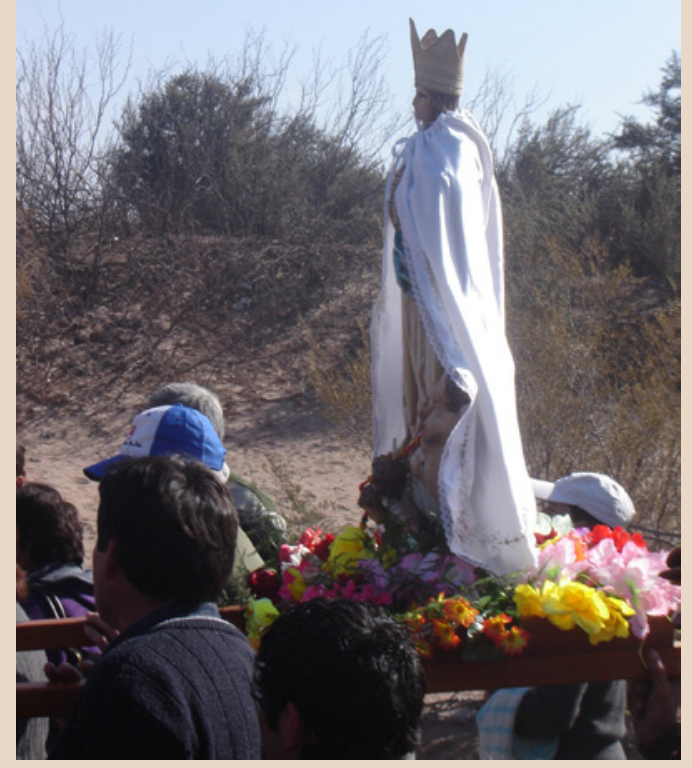


tan con la austeridad cromática del desierto, es paseada por todo el pueblo, y, aunque el cura y el policía encabecen la procesión, se escucha por momentos un exaltado grito cuyano, las guitarras de fondo, una tangible y certera presencia popular.

Así ornada, bonita, preside las misas oficiales, los bautismos, casamientos y comuniones que se llevan a cabo este día.

Luego es devuelta a la capilla, el agosto que viene se renovará la tradición y saldrán a la luz los colores, las canciones, los objetos populares que permanecerán contenidos por los gruesos muros de adobe de la capilla hasta el próximo año.

\section{ALGUNAS CONCLUSIONES}

La capilla y la fiesta de la Asunción son claras manifestaciones de la estética "mambí-forme" de resistencia.

Podemos detectar ciertas propuestas estéticas impuestas por estratos oficiales a las que se resisten otras que provienen desde lo popular y colectivo. Ambas se manifiestan alternativamente y en conjunto en los mismos espacios y durante el mismo período temporal.

De tal manera, a partir de mandatos oficiales, del ámbito culto, se ha construido la iglesia siguiendo modelos tradicionales, se ha colocado una imagen de la Virgen que es la que originalmente representa a la Virgen del Tránsito, se ha propuesto honrar a esa imagen celebrando una procesión, presidida por un sacerdote, el día que oficialmente está instaurado como día de la asunción.

Estas características podrían corresponder a cualquier país que practicara el culto católico. Sin embargo aparecen, afloran entre las grietas de esta estructura oficial los elementos de resistencia.

Por ello se improvisan bodegones, se cantan canciones sin temática religiosa, se come, se bebe abundantemente, se baila, se decora a la Virgen y al altar con flores, velas, mensajes, telas y brillos.

Frente a la estética oficial de muros blanqueados a la cal, formas regulares y austeras, se revelan las "mambí-formas" de colores, de la abundancia y el horror vacui. Porque no se puede negar el doble origen que implica ser latinoamericano, porque lo colectivo se toma sus revanchas y grita su nombre a través de los colores, la música y el olor a comida. Estas características mambises, calibanescas, son las que en definitiva nos distinguen, nos hacen "nosotros".

Por ello y debido a que nuestras expresiones poseen características es- 
téticas propias, debemos encontrar la manera de ponerlas en valor, a partir de nuestros criterios y categorías. Debemos dejar de usar parámetros de valoración importados que no tienen que ver con nuestra cultura y nuestra historia continental. Porque a nadie se le ocurriría ir al almacén por "una libra" de papas.

Conocer y valorar nuestras producciones estéticas a partir de nosotros mismos es el primer paso para que otros nos valoren y consideren.

\section{REFERENCIAS}

Bourdieu, P. (2000). La miseria del mundo. Efectos de lugar. pp. 119-124. Buenos Aires. Argentina: Fondo de Cultura Económica.

Fernández Retamar, R. (2004). Todo Caliban (pp. 1-151). Buenos Aires Argentina: Clacso.

Ponte, J. (1999) La fragilidad de la memoria. Representaciones, prensa y poder de una ciudad latinoamericana en tiempos del modernismo. Mendoza 1885/1910. $1^{\text {a }}$ ed., pp. 17-443, Mendoza. Argentina: Fundación CRYCIT.

Proyecto de Ley 156 (2007). Consultado en http:// www.1hcdn.gov.ar/proyxm/ expediente.asp?fundamentos $=$ si\&numexp $=5320-\mathrm{D}-2007$

Vicente, S. (2009). La producción estética(indígena y popular) en América Latina: Nuevos criterios de valor como expresión de la cultura de la resistencia. Santa Clara. Cuba: Inédito. 